2 Brasfield D, Hicks G, Soong SJ, Tiller RE. The chest roentgenogram in cystic fibrosis: a new scoring system. Pediatric 1979;63:24-9.

3 Pierce RJ, Brown DJ, Holmes M, Cumming G, Denison $D M$. The estimation of lung volume from chest radiographs using shape information. Thorax 1979;34:726-34.

4 Pierce RJ, Brown DJ, Denison DM. Radiographic, scin- tigraphic and gas-dilution estimates of individual lung and lobar volume. Thorax 1980;35:773-80.

5 Bush A, Denison DM. Use of different magnification factors to calculate radiological lung volumes. Thorax $1986 ; 41$ : 158-9.

6 Denison DM, du Bois R, Sawicka E. Pictures in the mind. Br $\mathcal{F}$ Dis Chest 1983;77:35-50.

\title{
Effects of inhaled lignocaine and adrenaline on capsaicin-induced cough in humans
}

\author{
L Hansson, B Midgren, J-A Karlsson
}

\begin{abstract}
Background - The hypothesis that adrenaline can augment and/or prolong the antitussive effect of nebulised lignocaine was examined.

Methods - The effect of inhaled lignocaine alone $(20 \mathrm{mg})$ and in combination with adrenaline $(400 \mu \mathrm{g})$ was studied on capsaicininduced cough in 10 healthy subjects.

Results - Cough was significantly reduced between five and 25 minutes by lignocaine. Adrenaline alone had no inhibitory effect and it neither augmented nor prolonged the antitussive effect of lignocaine. The subjective anaesthesia by lignocaine was short lasting (less than 15 minutes) and not altered by adrenaline, suggesting different sensory mechanisms for anaesthesia and cough suppression. Plasma concentrations of lignocaine were low $(<30 \mathrm{ng} / \mathrm{ml})$, not altered by adrenaline, and did not correlate with the local anaesthetic or the antitussive effect.

Conclusions - Lignocaine acts locally in the oropharynx and airways and adrenaline does not alter the effect or absorption of nebulised lignocaine on the human respiratory mucosa.
\end{abstract}

(Thorax 1994;49:1166-1168)

Department of Lung Medicine, University Hospital, S-221 85 Lund, Sweden

L Hansson

B Midgren

Discovery Biology, Rhône-Poulenc Rorer Ltd, London, UK J A Karlsson

Reprint requests to: Dr L Hansson.

Received 29 November 1993 Returned to authors 20 April 1994 Revised version received 27 June 1994 27 June 1994 19 July 1994 to examine the antitussive effect and the oropharyngeal numbness of inhaled lignocaine and adrenaline on capsaicin-induced cough in healthy human subjects. In addition, plasma levels of lignocaine were measured to determine the degree of systemic absorption.

\section{Methods}

Ten non-smoking healthy subjects (five women) of mean age 27 (range 18-33 years) took part in the study. They gave their written informed consent and the study was approved by the University Hospital medical ethics committee, Lund. Capsaicin (Sigma) was dissolved in ethanol and diluted with $0.9 \% \mathrm{NaCl}$ to 0.4 $\mu \mathrm{mol} / 1,2 \mu \mathrm{mol} / 1,10 \mu \mathrm{mol} / 1$, and $50 \mu \mathrm{mol} / 1$.

Capsaicin was inhaled by tidal breathing from a nebuliser (BIRD Asmastick, output $0.5 \mathrm{ml} / \mathrm{min}$ and mass median diameter $3 \mu \mathrm{m}$ ) filled with $2 \mathrm{ml}$ of solution. ${ }^{1}$ A microphone and tape recorder were used to register the sounds of breathing and cough. The number of coughs was counted from the tape recordings. Blood samples were drawn from an arm vein into heparinised tubes. All blood samples were centrifuged and plasma was then separated and stored at $-25^{\circ} \mathrm{C}$ until analysed by gas chromatography (Astra Alab, Södertälje, Sweden).

The antitussive effects of nebulised lignocaine $(20 \mathrm{mg})$, adrenaline $(400 \mu \mathrm{g})$, lignocaine in combination with adrenaline $(20 \mathrm{mg}+400 \mu \mathrm{g})$, and vehicle (saline) were studied on four separate study days. Treatments were administered in a randomised, double blind manner. Increasing concentrations of capsaicin $(0 \cdot 4-50 \mu \mathrm{mol} / \mathrm{l})$ were inhaled until a response of at least 10 coughs per minute was reached, and the concentration was then repeated and the mean response of the two challenges used as a baseline value. On each study day the chosen concentration was repeated. Capsaicin challenges were repeated five, $15,25,45$, and 60 minutes after treatment with the study drug. Subjects were asked to subjectively assess the level of oropharyngeal anaesthesia according to a five point scale immediately before each capsaicin challenge. Blood samples for determination of plasma levels of lignocaine were drawn before and 10, $20,30,45$, and 60 minutes after lignocaine inhalation. Kruskal-Wallis test was used at each 


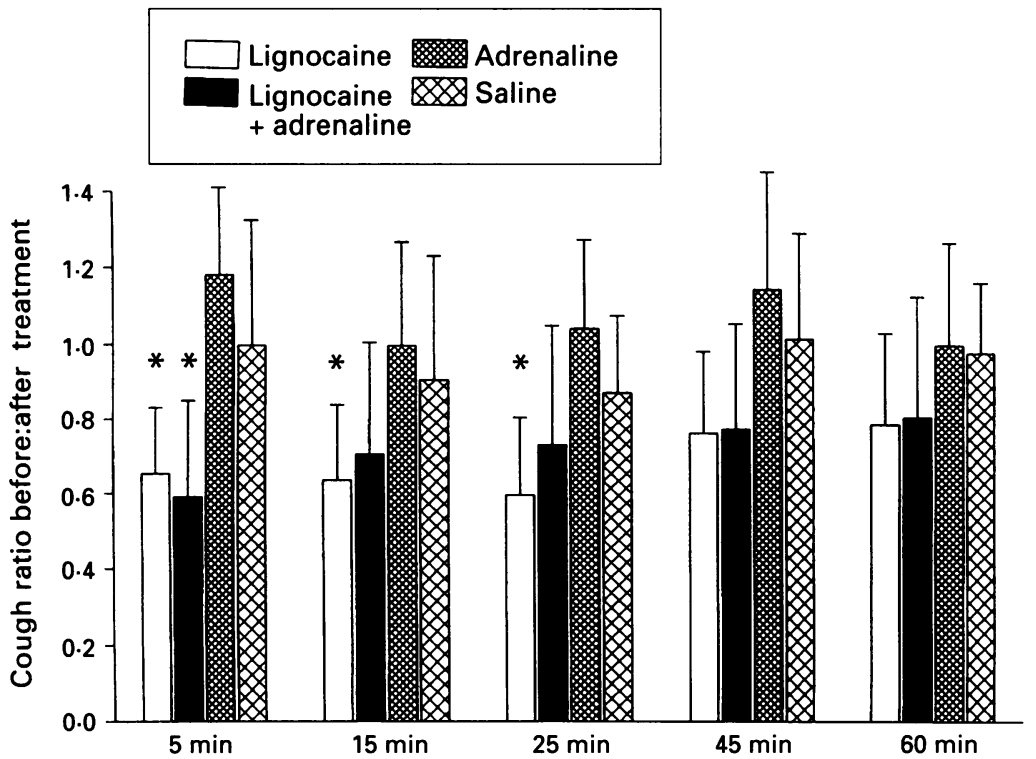

Figure 1 Ratio of capsaicin-induced coughs before:after treatment with lignocaine $(20 \mathrm{mg})$ alone, a combination of adrenaline $(400 \mu \mathrm{g})$ and lignocaine $(20 \mathrm{mg})$, adrenaline $(400 \mu \mathrm{g})$ alone, and placebo at different time points after treatment. Mean data are shown and error bars indicate $95 \% C I .{ }^{*} p<0.05$ compared with placebo, Wilcoxon's test.

time interval and Wilcoxon's test was used to compare statistically the number of coughs and the subjective oropharyngeal anaesthesia between the treatment periods. Analysis of variance was used to compare plasma concentrations of lignocaine.

\section{Results}

Capsaicin caused a highly reproducible cough response (fig 1, saline pretreatment). Inhaled lignocaine produced a mean $35 \%$ inhibition at five minutes (confidence interval (CI) $14 \%$ to $55 \%, \mathrm{p}<0.05)$ and was still significant after 15 and 25 minutes. The combination of lignocaine

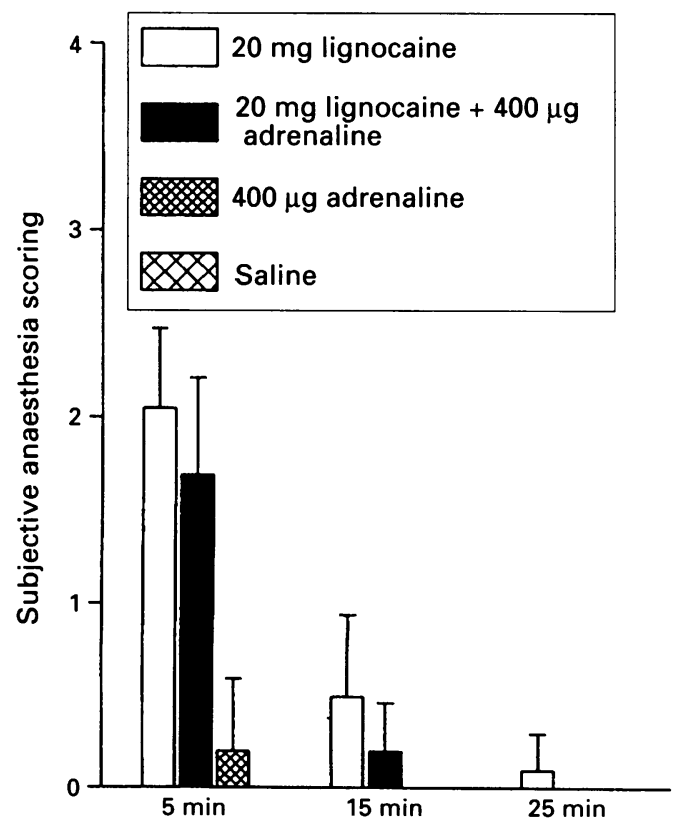

Figure 2 Subjective oropharyngeal anaesthesia according to a five point scale: $0=$ no anaesthesia, $1=$ noticeable anaesthesia, $2=$ slight anaesthesia, $3=$ moderate anaesthesia, $4=$ severe anaesthesia. Mean $+95 \%$ CI $(n=10)$ data are shown. and adrenaline produced the same degree of inhibition $(41 \%, \mathrm{CI} 11 \%$ to $71 \%, \mathrm{p}<0.05)$ as lignocaine alone at five minutes and it was not statistically significant at 15 and 25 minutes. There were no differences between lignocaine and the combination at any time. Adrenaline and vehicle were both without effect. The subjective feeling of anaesthesia produced by aerosols containing lignocaine was most intense at five minutes and lasted less than 15 minutes. The mean scores $(95 \% \mathrm{CI})$ at five minutes were $2.1(1.6$ to 2.5$)(\mathrm{p}<0.05)$ for lignocaine and $1.7(1.1$ to 2.3$)(\mathrm{p}<0.05)$ for the combination, $0.2(-0.2$ to 0.6$)$ for adrenaline alone, and $0.1(-0.1$ to 0.3$)$ for vehicle (fig $2)$. There were no differences between the two active treatments (fig 2). Plasma levels of lignocaine after 20 minutes were $19 \mathrm{ng} / \mathrm{ml}$ (range $10-30 \mathrm{ng} / \mathrm{ml}$ ) for lignocaine alone and $18 \mathrm{ng} / \mathrm{ml}$ (range $10-20 \mathrm{ng} / \mathrm{ml}$ ) for the combination and remained stable over 60 minutes $(p>0.05)$.

\section{Discussion}

This study showed that lignocaine in a dose of $20 \mathrm{mg}$ significantly reduced capsaicin-induced coughing. The duration of action of a local anaesthetic when infiltrated is prolonged by adrenaline, which is likely to be due to vasoconstriction at the site of injection. A low dose of lignocaine was used in this study to allow the detection of an interaction with adrenaline. However, adrenaline neither enhanced nor significantly prolonged the antitussive effect. The tracheobronchial mucosa has an extensive subepithelial vascular plexus and our data suggest that this dose of adrenaline, although rather high, was not able to significantly reduce mucosal blood flow or that other mechanisms determine the duration of action of lignocaine.

Recent studies have shown that reflex bronchoconstriction and cough are dissociated and mediated through different sensory pathways, and the absence of an antitussive effect of inhaled adrenaline in a bronchodilator dose supports the contention that the cough reflex in healthy subjects is independent of airway tone.

The duration of topical anaesthesia was short, but the antitussive effect was still significant 25 minutes after inhalation. The antitussive effect and the subjective anaesthesia seem to be mediated via different sensory mechanisms. Capsaicin-sensitive sensory neurones in the human respiratory tract are located superficially in the airway mucosa and we have recently shown that intrapulmonary nerve endings may be even more sensitive to capsaicin than those in the larynx. ${ }^{5}$ The antitussive effect is most likely to be exerted by the local anaesthetic deposited within the tracheobronchial tree, whereas the subjective symptoms are due to anaesthesia of the oropharynx and larynx.

The maximum plasma concentration after inhalation of $20 \mathrm{mg}$ of lignocaine was less than $20 \mathrm{ng} / \mathrm{ml}$, which is about $1 / 50$ of that attained after inhalation of $400 \mathrm{mg}$ with an ultrasonic nebuliser before bronchoscopy. ${ }^{6}$ This suggests 
that the antitussive effect is due to anaesthesia of the sensory nerves locally in the airway rather than to inhibition of impulse conduction in large conducting nerves or to suppression of a putative "cough centre" in the central nervous system. Further support for this view comes from a study which showed that a high plasma concentration ( $>3000 \mathrm{ng} / \mathrm{ml}$ ) was necessary to inhibit the cough reflex after intravenous administration. ${ }^{7}$

The present study has shown that capsaicininduced cough can be reduced by inhaled lignocaine through an action locally in the tracheobronchial tree. Inhibition of the cough reflex was significantly more pronounced than the subjective sensation of oropharyngeal anaesthesia, suggesting the involvement of separate sensory mechanisms. Adrenaline had no antitussive effect and did not alter the response to inhaled lignocaine, indicating that the combined use of these two agents on the respiratory mucosa offers no advantage over lignocaine alone.

This study was supported by grants from the Swedish Hear and Lung Foundation and Astra-Draco $A B$, Lund, Sweden. The authors would like to thank Mr Göran Randwall and Mrs Carin Rolf for technical assistance.

1 Midgren B, Hansson L, Karlsson J-A, Simonsson BG, Persson CGA. Capsaicin-induced cough in humans. Am Rev Respir Dis 1992;146:347-51.

2 Howard P, Cayton RM, Brennan SR, Anderson PB. Lignocaine aerosol and persistent cough. $\mathrm{Br} \mathcal{F}$ Dis Chest 1977 71:19-24.

3 Sanders RV, Kirkpatrick MB. Prolonged suppression of cough fter inhalation of lidocaine in a patient with sarcoid. $\mathscr{Y A M A}$ 1984;252:2456-7.

4 Laitinen LA, Robinson NP, Laitinen A, Widdicombe JG Relationship between tracheal mucosal thickness and vasRelationship between tracheal mucosal thickness and vas-
cular resistance in dogs. $₹$ Appl Physiol 1986;61:2186-93.

cular resistance in dogs. F Appl Physiol 1986;61:2186-93.
5 Hansson L, Wollmer P, Dahlbäck M, Karisson J-A. Regional Hansson L, Wollmer P, Dahlbäck $M$, Karisson J-A. Regional
sensitivity of human airways to capsaicin-induced cough. Am Rev Respir Dis 1992;145:1191-5.

6 Gove RI, Wiggins J, Stableforth DE. A study of the use of ultrasonically nebulized lignocaine for local anaesthesia during fibreoptic bronchoscopy. $\mathrm{Br} \mathcal{F}$ Dis Chest 1985;79. 49-59.

7 Yukioka H, Yoshimoto N, Nishimura K, Fujimori M. Intravenous lidocaine as a suppressant of coughing during tracheal intubation. Anesth Analg 1985;64:1189-92. 